\title{
Renal cell carcinoma in Yemeni patients: a review of 67 cases
}

\author{
Abstract \\ Objective: To determine the age, sex, pattern of presentation, geographical distribution, \\ pattern of management and histopathology subtypes of RCC in Yemeni patients.
}

Patients and methods: A retrospective study was performed covering the period between January 2004 and December 2008. A total of 67 adult patients had been diagnosed to have RCC during this period. Information extracted and analyzed included the age of the patient, sex, presentation, histopathology subtype $\&$ grade and management.

Results: The mean age of the patients was $50.3 \pm 13.3$ years (range $22-80 \mathrm{yrs}$ ). The male: female ratio was $1: 1.1$. The duration of symptoms varied widely from few weeks to a few years (range 0.5-94 months). 11 cases (16.4\%) presented with the so-called "too late triad" consisting of loin pain, haematuria and palpable mass. 7 patients $(3 \%)$ were diagnosed incidentally. 65 patients $(97 \%)$ were operated upon; radical nephrectomy was the standard procedure in 60 patients $(92.5 \%), 5$ patients $(8.3 \%)$ had radical nephrectomy and IVC thrombectomy. Partial nephrectomy was indicated in 4 patients $(6 \%)$. The most common histopathological subtype was clear cell type (43\%) and Chromophobic type (19.4\%).

Conclusion: We concluded that RCC in adult Yemenis is presented in an earlier age with predominant female gender. Incidental detection of renal carcinoma is lower as compared to western world. Post surgical morbidity and mortality was compatible to that reported in most series

Keywords: renal tumor, renal cell carcinoma, hematuria, loin pain, loin swelling, weight loss
Volume 3 Issue 2 - 2016

\author{
Shukri Alfalahi, Tawfik H Al Baadani, \\ Mohammed Babakri,Abdulelah Ghilan \\ Department of Urology,Althawra Modern Teaching hospital, \\ Yemen
}

Correspondence: Shukri Alfalahi, Department of Urology, Nephrology \& Urology center, Althawra Modern Teaching hospital, Sana'a, Yemen, Tel 96771 I70130I, Email salamalhasani@hotmail.com

Received: June 03,2016 | Published: April 12, 2016

\section{Introduction}

Kidney cancer accounts for nearly $2 \%$ of all malignancies globally It occurs with 189000 new cases and 91000 deaths from the disease annually. ${ }^{1}$ More than $80 \%$ of kidney cancers are renal cell carcinomas. ${ }^{2}$ RCC, which accounts for $2 \%$ to $3 \%$ of all adult malignant neoplasms, is the most lethal of the urologic cancers. Traditionally, more than $40 \%$ of patients with RCC have died of their cancer, in contrast with the $20 \%$ mortality rates associated with prostate and bladder carcinomas. ${ }^{3}$ Approximately 57,760 new cases of RCC and 12,980 deaths are expected to have occurred in the United States in 2009. One fourth to one third of patients present with metastatic disease. ${ }^{4}$ The increasing incidence seen in most parts of the world cannot fully be explained by increasing availability to medical service and use of imaging procedures but also to increases in the prevalence of etiologic risk factors. The incidence globally of kidney cancer varies considerably among different populations and regions. The rates are highest in Western and Eastern Europe, North America, Australia and Scandinavia, intermediate in Southern Europe and Japan, and low elsewhere in Asia, Africa and the Pacific. ${ }^{1}$ Few studies are available in the developing countries such as that done in Pakistan, Nigeria and other parts of Africa which indicate that this tumor were often diagnosed in advanced stage. In contrast, in most developed countries more than $50 \%$ of these tumors are incidentally detected. ${ }^{5}$ In Yemen there is no any previous study or report describing RCC in Yemeni patients. And the present study will be the first review undertaken to determine the age, sex, pattern of presentation, geographical distribution, and pattern of management and histopathology subtypes of RCC in Yemeni patients. The study was carried out at the Urology \& Nephrology center, Althawra Typical Modern Hospital (TMGH) which considered the only referral urology center provides specialized health care for all over Yemen.

\section{Patients and methods}

In this descriptive retrospective study, we reviewed the data of all patients managed for renal tumors who admitted in the urology department at The Urology \& Nephrology center which considered the first and only referral urology center in Yemen and provides specialized tertiary services for all Yemeni governorates. After hospital ethical committee clearance, data was obtained from patients files retrieved from the hospital archives and from the histopathology records. The study submitted from 2004 through December 2008. We estimated that a five-year period would provide enough data for our study. The hospital records of 81 adult patients (age over 17 years) were reviewed; only 67 cases of renal cell carcinoma were confirmed with tissue diagnosis and were included in this study. After selecting the sample, a worksheet was prepared to collect data, which were organized in a database using the software SPSS ${ }^{\circledR}$, version 15 , for descriptive analysis. All the categorical variables were summarized using frequencies and percentages. The cases worksheets were analyzed for age, sex, residency, mode of presentation, duration of the symptoms, type of management, and the duration of hospital stay. The tumor laterality, polarity, size and histopathological typing \& grading were also recorded (Tables $1 \& 2$ ). All patients were evaluated for past medical, surgical, family and drug history so that systemic illnesses, associated co- morbidity and possible etiological factors were noted. Local and general examination was done for all patients.

All patients underwent standard laboratory investigations including complete blood count, renal and liver function tests and urine analysis. Radiological tests for diagnosis and staging include chest roentgenography, intravenous urogram, abdominal ultrasound and abdominal computerized tomography. Renal cell carcinoma was considered to be incidental, when the diagnostic evaluation was not 
initiated secondary to any symptoms or signs associated with renal cell carcinoma. Lesions were considered to be symptomatic, SRCC, when patients presented with symptoms due to the tumor itself (e.g. flank mass, flank pain and hematuria) or due to advanced disease (such as weight loss or bone pain). Tumor staging of RCC was classified according to the International TNM Staging System, (Tables $3 \& 4$ ). 32 patients $(47.8 \%)$ were males and $35(52.2 \%)$ were females. The male to female ratio was $1: 1.1$. Their ages ranged between $22-80$ years, with the mean age of $50.3 \pm 13.3$. The mean age for the male patients was $55.25 \pm 13.3$ (range 35-80), while the mean age for the female patients was $45.8 \pm 11.8$ (range 22-70). The duration of symptoms varied widely from few weeks to a few years, with mean duration of symptoms $9 \pm 12.6$ months (range $0.5-94) .11$ cases $(16.4 \%$ ) presented with the so-called "classical triad" or "too late triad" consisting of loin pain, haematuria and palpable mass. 7 patients $(3 \%)$ were diagnosed incidentally by ultrasound for non urological purposes in. 3 of the incidentally diagnosed RCC were Stage I, 3 were Stage III and 1 was Stage VI (Figure 1).

\section{Male to Female Ratio}

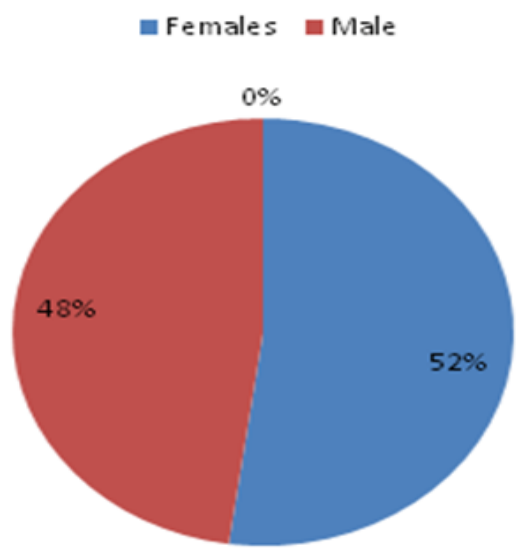

Figure I The sex incidence of RCC.

The tumor was located on the right side in 41 patients $(61.2 \%)$ and on the left side in 26(38.8\%). The tumor was in a solitary kidney in 4 patients $(6 \%), 3$ were functional solitary and 1 surgical solitary. These tumors were occupying the lower pole in 15 patients $(22.4 \%)$, the upper pole in 13 patients (19.4\%) and the middle pole in 7 patients $(10.4 \%)$. It was not specified in the rest, mainly due to the large size of the tumor extending beyond one pole. Only 7 patients $(10.4 \%)$ had IVC tumor thrombosis, the thrombus was below the diaphragm in 4 patients and above the diaphragm in 3 . All these patients were in stage III \& VI. The maximal diameter of the tumor mass removed at surgery ranged between 3 and $20 \mathrm{~cm}$. with average diameter of $9.3 \mathrm{~cm} .15$ patients $(22.4 \%)$ were presented in Stage I, $21(31.3 \%)$ in Stage II, $21(31.3 \%)$ in Stage III and $10(14.9 \%)$ in Stage VI. Table 5 shows the various presentations by stage of RCC and average diameter of the tumor. 65 patients $(97 \%)$ were operated upon: radical nephrectomy was the standard procedure in 60 patients $(92.5 \%)$, amongst these patient 5 patients $(8.3 \%)$ had radical nephrectomy and IVC thrombectomy. Partial nephrectomy was indicated in 4 patients $(6 \%)$, all of them due to the presence of the tumor in a solitary kidney. All patients who underwent partial nephrectomy were discharged with renal function test equal to their preoperative baseline except one patient who developed chronic renal failure and discharged on regular haemodialysis. 1 patient $(1.5 \%)$ underwent abdominal exploration and had unrespectable tumor. Only 2 patients $(3 \%)$ who not operated, one of them due to advanced tumor and one were unfit for surgery. Both patients had IVC tumor thrombus. Amongst the 60 patients with radical nephrectomy, 52(87\%) had no postoperative surgical complications, 3 patient (5\%) died of pulmonary embolism, 3(5\%) developed lower limp DVT. Other surgical complications include wound sepsis and peritonitis in one patient each $(3 \%)$. The average duration of postoperative hospital stay was 5.8 days (range 2-20 days). 13 patients (22\%) who were admitted in the intensive care unit (ICU) in the post operative period with average duration of 3.3 days (range 1-14 days). Table 6 shows the average postoperative hospital stay by the stage of presentation.

Table I Histopathology subtypes of RCC

\begin{tabular}{llll}
\hline Histopathology & & $\begin{array}{l}\text { No. of } \\
\text { patients }\end{array}$ & Percent \% \\
\hline Conventional (46\%) & Clear cell & 29 & 43.3 \\
& Granular & 1 & 1.5 \\
& Mixed & 1 & 1.5 \\
& Total & 31 & 46 \\
Chromophobic & & 13 & 19.4 \\
Papillary & & 5 & 7.4 \\
Collecting duct & & 1 & 1.5 \\
Undetermined & & 17 & 25.4 \\
Total & & 67 & 100
\end{tabular}

Table 2 Histopathological Grading of RCC

\begin{tabular}{llll}
\hline Histopathology & & $\begin{array}{l}\text { No. of } \\
\text { Patients }\end{array}$ & Percent \% \\
\hline Conventional (46\%) & Clear cell & 29 & 43.3 \\
& Granular & 1 & 1.5 \\
& Mixed & 1 & 1.5 \\
& Total & 31 & 46 \\
Chromophobic & & 13 & 19.4 \\
Papillary & & 5 & 7.4 \\
Collecting duct & & 1 & 1.5 \\
Undetermined & & 17 & 25.4 \\
Total & & 67 & 100 \\
\hline
\end{tabular}

Only 6 patients $(9 \%)$ gave history of tobacco/cigarette smoking and 2 patients (3\%) history of tobacco chewing. Urological disorders was obtained in 10 patients $(15 \%), 6$ of them had urolithiasis, 2 with recurrent urinary tract infection and 2 patient had PUJO. 8 patients $(12 \%)$ had diabetes mellitus, 6 of them on glibenclamide oral treatment and one on insulin. 7 patients (10.5\%) were hypertensive, 3 treated with angiotensin converting enzyme inhibitor ACEI and 2 with calcium channel blocker CCB. 1 patient $(1.5 \%)$ had both diabetes mellitus and hypertension. 1 patient $(1.5 \%)$ had hypothyroidism on 
thyroxin replacement treatment. Past surgical history are listed in Table 7. Other dietary and environmental risk factors could not be studied from retrospective data available.

Table 3 International TNM Staging System for Renal Cell Carcinoma

\begin{tabular}{llll}
\hline Stage I & TI & No & M0 \\
Stage II & T2 & No & M0 \\
Stage III & TI or T2 & NI & M0 \\
& T3 & N0 or NI & M0 \\
Stage IV & T4 & any N & M0 \\
& any T & N2 & M0 \\
& any T & any N & MI \\
\hline
\end{tabular}

Table 4 International TNM Staging System for Renal Cell Carcinoma

\section{T: Primary tumor}

TX: Primary tumor cannot be assessed

TO: No evidence of primary tumor

Tla:Tumor $\leq 4.0 \mathrm{~cm}$ and confined to the kidney

TIb:Tumor $>4.0 \mathrm{~cm}$ and $\leq 7.0 \mathrm{~cm}$ and confined to the kidney

T2: Tumor $>7.0 \mathrm{~cm}$ and confined to the kidney

T3a:Tumor invades adrenal gland or perinephric fat but not beyond Gerota's fascia

T3b:Tumor extents into the renal vein (or its segmental branches) or vena cava below diaphragm

T3c:Tumor extends into the vena cava above the diaphragm or invades the wall of the vena cava

T4:Tumor invades beyond Gerota's fascia

$\mathrm{N}$ : Regional lymph nodes

NX: Regional lymph nodes cannot be assessed

N0: No regional lymph nodes metastasis

$\mathrm{NI}$ : Metastasis in a single regional lymph node

N2: Metastases in more than one regional lymph node

M: Distant metastases

MX: Distant metastasis cannot be assessed

M0: No distant metastasis

MI: Distant metastasis present

\section{Stage grouping}

$\begin{array}{llll}\text { Stage I } & \text { TI } & \text { No } & \text { M0 } \\ \text { Stage II } & \text { T2 } & \text { No } & \text { M0 } \\ \text { Stage III } & \text { TI or T2 } & \text { NI } & \text { M0 } \\ & \text { T3 } & \text { No or NI } & \text { M0 } \\ \text { Stage IV } & \text { T4 } & \text { any N } & \text { M0 } \\ & \text { any T } & \text { N2 } & \text { M0 } \\ & \text { any T } & \text { any N } & \text { MI }\end{array}$

Table 5 RCC by stage and size

\begin{tabular}{llll}
\hline Stage & $\begin{array}{l}\text { No of } \\
\text { patients }\end{array}$ & $\begin{array}{l}\text { \% of } \\
\text { Patients }\end{array}$ & $\begin{array}{l}\text { Mean diameter } \\
\text { of the tumor } \\
(\mathbf{c m} .)\end{array}$ \\
\hline stage 1 & 15 & $22.40 \%$ & 5.3 \\
stage 2 & 21 & $31.30 \%$ & 10 \\
stage 3 & 21 & $31.30 \%$ & 10 \\
stage 4 & 10 & $14.90 \%$ & 12.6 \\
Total & 67 & $100.00 \%$ & 9.3 \\
\hline
\end{tabular}

Table 6 Average postoperative hospital stay by the stage of presentation

\begin{tabular}{ll}
\hline Stage & $\begin{array}{l}\text { Post operative hospital } \\
\text { stay (Average) }\end{array}$ \\
\hline stage I & 5.07 \\
stage 2 & 5.05 \\
stage 3 & 5.7 \\
stage 4 & 9.33 \\
Total & 5.87 \\
\hline
\end{tabular}

Table 7 Past surgical history

\begin{tabular}{lll}
\hline Past surgical history & $\begin{array}{l}\text { No. of } \\
\text { patients }\end{array}$ & Percent \% \\
\hline Herrniorhaphy & 4 & 6 \\
$\begin{array}{l}\text { Pyelolithotomy } \\
\text { Oophorectomy for haemrrhagic } \\
\text { ovarian cyst }\end{array}$ & $\mathrm{I}$ & 1.5 \\
$\begin{array}{l}\text { Contralateral nephrectomy } \\
\text { Orchiectomy }\end{array}$ & $\mathrm{I}$ & 3 \\
Adenomyectomy & $\mathrm{I}$ & 1.5 \\
Ceaserian section & $\mathrm{I}$ & 1.5 \\
Cholecystectomy & $\mathrm{I}$ & 1.5 \\
Appendectomy & $\mathrm{I}$ & 1.5 \\
Laparatomy for ectopic pregnancy & $\mathrm{I}$ & 1.5 \\
Lipoma excision & $\mathrm{I}$ & 1.5 \\
Total & 15 & 1.5 \\
\hline
\end{tabular}

\section{Discussion}

As mentioned earlier, this study was undertaken in the first and only referral urology center in Yemen, so the patients included in this review came from various Yemeni governorates. Table 8 showed the geographical distribution of RCC in Yemen. It is noticeable that $17.9 \%$ of RCC cases came from Dhamar and this result not correlated 
with the population distribution in this governorate. This observation if confirmed later, would give alarm for the importance to study the suspected social and environmental risk factors in this area by more reports in the future. As reported in many series renal cell carcinoma affect males predominantly. Male to female ratio are generally between 1.5:1 and 2.5:1. ${ }^{6}$ This was not our observation, where the ratio of 1:1 indicates a higher occurrence in Yemeni females. For a lesser extent a similar observation was reported in Saudi Arabia by Talic and El Faqih on a group of 33 Saudi patients with RCC; the M:F ratio was $1.3: 1$.

Table 8 Geographical distribution for RCC in Yemen

\begin{tabular}{lll}
\hline Residency & Frequency & Percent \\
\hline Dhamar & 12 & 17.91045 \\
Taiz & 9 & 13.43284 \\
Ibb & 9 & 13.43284 \\
Sanaa city & 7 & 10.44776 \\
Sanaa gov & 6 & 8.955224 \\
Hajja & 5 & 7.462687 \\
Hodeida & 4 & 5.970149 \\
Dahela & 4 & 5.9 \\
Amran & 3 & 4.477612 \\
Abyan & 2 & 2.985075 \\
Aden & I & 1.492537 \\
Hadramout & I & 1.492537 \\
Shabwa & I & 1.492537 \\
Mahweet & I & 1.492537 \\
Mareb & I & 1.492537 \\
ALBayda & I & 1.492537 \\
Total & 67 & 100 \\
\hline
\end{tabular}

This observation is difficult to explain. But if confirmed in future reports, would indicate the necessity to investigate Yemeni females closely for suspected risk factors. The mean age for our patients were $50.3 \pm 13.3$ (range 22-80), with peak incidence in the fourth and fifth decades of life. Thus, the peak incidence of RCC occurs about two decades lower than the 50-70 years peak incidence reported amongst Caucasians. ${ }^{8} 32 \%$ of our patients were aged $\leq 40$ years old this result is about sixth folds larger than what reported by Jae Hee Suh et al on a group of 838 cases of renal cell carcinoma, ${ }^{2}$ only $5.2 \%$ of their patients were $\leq 40 .{ }^{9}$ This indicates the high incidence of RCC in Yemeni younger adults ( $\leq 40$ years old). This review showed that flank pain $(70 \%)$, haematuria $55.22 \%$, palpable mass $37.3 \%$ are prominent symptoms of RCC in our patients. The classic triad of flank pain, gross haematuria, and palpable abdominal mass "too late triad" was observed in $16.41 \%$ of our patients. Which denotes advanced disease presentation and late detection of the tumor, in contrast to that reported in most series, in which this triad is now rarely found in the developed countries due to early or incidental diagnosis of RCC. ${ }^{10}$ Our finding is consistent with that reported by some reviews in other developing countries, like that reported by Badmus TA et al., ${ }^{5}$ on a group of 18 Nigerian patients which indicated that most cases still present late with loin pain. Loin swelling and haematuria. Paraneoplastic syndromes are found in $20 \%$ of patients with RCC. ${ }^{10}$ In current study $25.3 \%$ of patients presented with anaemia, also polycythemia, hypertension, abnormal liver function, hypercalcemia and hepatomegaly were also detected in our patients but less frequently than expected (Table 9).

Table 9 Clinical features at presentation

\begin{tabular}{lll}
\hline Clinical feature & N & $\%$ \\
\hline Flank pain & 47 & 70 \\
Haematuria & 31 & 46 \\
Palpable mass & 26 & 39 \\
Anaemia & 16 & 24 \\
Weight loss & 4 & 6 \\
Bone pain & 2 & 3 \\
Bilateral lower limp swelling & $\mathrm{I}$ & 1.5 \\
Pleural effusion with respiratory distress & $\mathrm{I}$ & 1.5 \\
Polycythemia & $\mathrm{I}$ & 1.5 \\
Hypertension & $\mathrm{I}$ & 1.5 \\
Abnormal liver function & $\mathrm{I}$ & 1.5 \\
Hypercalcemia & $\mathrm{I}$ & 1.5 \\
Hepatosplenomegally & $\mathrm{I}$ & 1.5 \\
\hline
\end{tabular}

The incidentally diagnosed RCC was found with only in $10 \%$ of our patient, and this result is so far from that in developed countries in which more than $50 \%$ of RCC are now incidentally discovered very early in these communities partly because of increased use of imaging procedures there. ${ }^{11}$ Table 10 showed the incidence of incidental presentation of RCC in various developing communities. The average size of the tumor mass removed at surgery in this series was $9.3 \mathrm{~cm}$. in the maximal diameter (range 3-20 cm.). Tumor size has ranged from 5 to $8 \mathrm{~cm}$ in most series, The mean size reported in the literature was $5.3 \mathrm{~cm} .{ }^{12}$ This result In Yemeni patients indicates that RCC in our community are relatively bigger at presentation. This finding also closely reflects the late presentation in most of our patients in contrast to early detection in developed societies. Abdominal Ultrasonography was found very useful in establishing the diagnosis in all our patients. The value of surgery in the management of RCC lies on the fact that RCC is relatively resistant to systemic therapy like radiotherapy, chemotherapy or hormone therapy. ${ }^{13}$ Radical nephrectomy, which has been the standard procedure in 60 patients, and was successfully carried out with IVC thrombectomy in 5 patients and in one patient with locally advanced tumor with good results. Morbidity after radical nephrectomy was in 5 patients (8\%), 3 of them had lower limp DVT. Two other patients had minor complications. Amongst the patients with radical nephrectomy, mortality were in 3 patients $(5 \%)$, all of them died of pulmonary embolism few days postoperative. Two of the three died patients had IVC thrombosis, in high level in one of them. Other studies reported mortality rate of $4 \%$ and $8 \%{ }^{14}$ There is no intraoperative death.

Presentation by stage is compared to other series in (Table 11) 
$53.7 \%$ of our patients presented in Stage I and II and $14.9 \%$ presented in Stage VI. These results are compatible with other reports and suggest that there is no delay in the diagnosis and management of RCC patients in Yemen. But a result of $22.4 \%$ for stage I is more lesser than reported in other series and may indicate the delay in the patient presentation to the primary medical services as well as the delay in the referral to the tertiary center. The average duration of postoperative hospital stay was 5.8 days (range 2-20 days). Faisal Ghaffar et al., ${ }^{15}$ reported mean hospital stay duration of 13 days. Like mentioned in the literature the most common histopathology subtype in our patients was clear cell type (43\%). Chromophobic type also showed a predominance pattern amongst our patients with a percent of $(19.4 \%)$ which take a higher incidence than reported in most series. ${ }^{10}$

Table 10 Incidental presentation of RCC in developing communities

\begin{tabular}{lll} 
Source & Country & Result \% \\
Paresh Jain et al. (63) & India & $28 \%$ \\
Talic \& El Faqih (1996) & Saudi Arabia & $30 \%$ \\
Current study & Yemen & $10 \%$ \\
\hline
\end{tabular}

Table I I Presentation by stage comparison

\begin{tabular}{lllll} 
Source & Stage I & Stage II & Stage III & Stage VI \\
$\begin{array}{l}\text { Skinner et al. } \\
\text { (197I) }\end{array}$ & $33 \%$ & $7 \%$ & $35 \%$ & $25 \%$ \\
$\begin{array}{l}\text { Talic \& El Faqih } \\
(1996)\end{array}$ & $58 \%$ & $15 \%$ & $6 \%$ & $21 \%$ \\
Current study & $22.40 \%$ & $31.30 \%$ & $31.30 \%$ & $14.90 \%$ \\
\hline
\end{tabular}

The etiology of RCC is poorly understood. The only generally accepted environmental risk factor for RCC is tobacco exposure. Also cadmium exposure, haemodialysis in end stage renal failure and acquired cystic disease of the kidney were established as reported risk factors. ${ }^{6}$ This review showed that these factors are not important in etiology pathogenesis in our community as only $(11 \%)$ of our patients gave history of tobacco exposure and none of them was industrial worker. Also no cases of acquired cystic disease of the kidney or end stage renal failure were encountered in our study. And by a retrospective study there is no any possibility to establish whether there are any particular risk factors unique to Yemeni population. ${ }^{16-20}$

\section{Conclusion}

RCC in adult Yemen is presented in an earlier age with predominant female gender with main geographical distribution in the central region (Dhamar, Ibb and Taiz). Most cases still presented late with loin pain, palpable mass and haematuria. Incidental detection of renal carcinoma as compared to symptomatic tumors is lower in Yemen as compared to western world. Radical nephrectomy is safe and beneficial in operable RCC with morbidity and mortality compatible to that reported in most series.

\section{Acknowledgments}

None.

\section{Conflicts of interest}

The author declares there is no conflict of interest.

\section{References}

1. Ferlay J, Bray P, Pisani P. Globocan 2000: Cancer Incidence, Mortality and Prevalence Worldwide, Version 1.0. Iarc Cancerbase No. 5, Iarcpress, Lyon, France; 2001.

2. Amsellem-Ouazana D, Allory Y, Viellefond A. Survival and Prognostic Factors of Papillary Renal Cell Carcinoma (Rcc): Long Term Follow-up of 43 Patients. J Urol. 2002;167:192.

3. Landis SH, Murray T, Bolden S, et al. Cancer statistics. CA Cancer $J$ Clin. 1999;49(1):8-31.

4. Society, American Cancer. Cancer reference information, detailed guide: kidney cancer staging. American Cancer. 2001.

5. Badmus TA, Salako AA, Arogundade FA, et al. Malignant Renal Tumors in Adults: A Ten-Year Review in a Nigerian Hospital. Saudi J Kidney Dis Transpl. 2008;19(1):120-126.

6. Luciani LG, Cestari R, Tallarigo C. Incidental Renal Cell CarcinomaAge and Stage Characterization and Clinical Implications: Study of 1092 Patients (1982-1997). Urology. 2002;56(1):58-62.

7. Lindblad P. Epidemiology of renal cell carcinoma. Sc and J Surg. 2004;93(2):88-96.

8. Talic RF, El Faqih SR. Renal Tumors in Adult Saudi patients: A review of 43 cases. Ann Saudi Med. 1996;16(5):517-520.

9. Chow WH, Devesa SS, Warren JL, et al. Rising Incidence of Renal Cell Cancer in the United States. JAMA. 1998;281(17):1628-1638.

10. Campbell SC, Novick AC, Bukowski RM. Renal tumors. In: Wein Aj Kavoussi Lr, et al., editors, Campbell-Walsh Urology. 9th ed. Philadelphia: Saunders, USA, 2008. p. 1567-637.

11. Amin MB, Corless CL, Renshaw AA, et al. Papillary (chromophil) renal cell carcinoma: histomorphologic characteristics and evaluation of conventional pathologic prognostic parameters in 62 cases. $\mathrm{Am} \mathrm{J}$ Surg Pathol. 1997;21(6):621-635.

12. Jain $P$, Surdas R, Aga $P$, et al. Renal cell carcinoma: Impact of mode of detection on its pathological characteristics. Indian J Urol. 2009;25(4):479-482.

13. Yaycioglu O, Rutman Mp, Balasubramaniam M, et al. Clinical and pathologic tumor size in renal cell carcinoma: difference, correlation, and analysis of the influencing factors. Uorology. 2002;60(1):33-38.

14. Robson CJ, Churchill BM, Anderson W. The Results of Radical Nephrectomy for Renal Cell Carcinoma. J Urol. 1969;101(3):297-301.

15. A Faisal Ghaffar, M Ali Sajid, K Anwar. Transperitoneal Approach for Radical Nephrectomy: Five Years Experience at Pakistn Institute of Medical Sciences, Islamabad, Pakistan. J Ayub Med Coll Abbottabad. 2007;19(3):15-18.

16. Suh JH, Oak T, Ro JY, et al. Clinicopathologic Features of Renal Cell Carcinoma in Young Adults: A Comparison Study with Renal Cell Carcinoma in Older Patients. Int J Clin Exp Pathol. 2009;2(5):489-493.

17. Patel NP, Lavengood RW. Renal cell carcinoma: natural history and results of treatment. J Urol. 1978;119(6):722-726.

18. Stephenson AJ, Hakimi AA, Snyder ME, et al. Complications of radical and partial nephrectomy in a large contemporary cohart. J Urol. 2004;171(1):130-134.

19. Guinan PD, Vogelzang NJ, Fremgen AM. Renal cell carcinoma: tumor size, stage and survival. J Urol. 1995;(153):901-903.

20. Skinner DG, Colvin RB, Vermillion CD, et al. Diagnosis and management of renal cell carcinoma: A clinical and pathologic study of 309 cases. Cancer. 1971;28(5):1165-1177. 